\title{
AUTOMORPHISMS OF K(H) WITH RESPECT TO THE STAR PARTIAL ORDER
}

\section{Gregor Dolinar, Alexander Guterman and Janko Marovt}

Abstract. Let $H$ be a separable infinite dimensional complex Hilbert space, and let $K(H)$ be the set of all compact bounded linear operators on $H$. In the paper we characterize the bijective, additive, continuous maps on $K(H)$ which preserve the star partial order in both directions.

Mathematics subject classification (2010): 06A06, 15A03, 15A04, 15 A86.

Keywords and phrases: Star partial order, minus partial order, preserver.

\section{REFERENCES}

[1] J. B. Conway, A course in functional analysis, Springer-Verlag, New York, 1990.

[2] M. P. DRAZIN, Natural structures on semigroups with involution, Bull. Amer. Math. Soc. 84 (1978), $139-141$.

[3] G. Dolinar, J. Marovt, Star partial order on B(H), Linear Algebra Appl. 434 (2011), 319-326.

[4] A. E. Guterman, Monotone additive matrix transformations, Math. Notes 81 (2007), 609-619.

[5] R. E. HARTwig, How to partially order regular elements, Math. Japon. 25 (1980), 1-13.

[6] A. KIRSCH, An introduction to the mathematical theory of inverse problems, Springer, New York, 1996.

[7] P. LEGIŠA, Automorphisms of $M_{n}$, partially ordered by the star order, Linear and Multilinear Algebra 54 (2006), 157-188.

[8] M. Z. NASHed (ED.), Generalized inverses and applications, Academic Press, New York-London, 1976.

[9] R. Penrose, A generalized inverse for matrices, Proceedings of the Cambridge Philosophical Society 51 (1955), 406-413.

[10] L. Smithies, R. S. VARgA, Singular value decomposition Geršgorin sets, Linear Algebra Appl. 417 (2006), 370-380.

[11] P. ŠEMRL, Automorphisms of $B(H)$ with respect to minus partial order, J. Math. Anal. Appl. 369 (2010), 205-213. 